\title{
infância, experiência e educação: apontamentos a partir de reflexões sobre a pequena infância
}

\author{
eloisa acires candal rocha ${ }^{1}$ \\ universidade do oeste de santa catarina - brasil \\ márcia buss-simão ${ }^{2}$ \\ universidade do sul de santa catarina - brasil
}

resumo

O presente artigo traz reflexões que envolvem a infância e a experiência a partir da área da educação e, particularmente, das ponderações em torno das pesquisas com crianças pequenas de educação infantil. Os apontamentos impõem limites relativos a este lugar de estudo e delimitam estes como parte de uma crítica e autocrítica da educação e das possibilidades de consolidação de uma Pedagogia da Infância. Nesta direção, no artigo se toma para esta reflexão a análise do sentido da experiência para as principais teorias educacionais ou projetos educativos para a educação na infância, a fim de levar a uma demarcação dos contornos da experiência educativa na/da infância institucionalizada. Para tal, apresenta alguns elementos relativos à experiência educativa como experiência social a partir de estudos empíricos que dão visibilidade às ações das crianças como parte de suas vidas nos coletivos infantis. Por fim, indica como desafios para a possível consolidação de uma Pedagogia da Infância uma aproximação da Pedagogia às manifestações infantis, a criança em situação e as possibilidades de os processos educativos se pautarem na escuta, na dialogicidade e nas relações, possibilitando incluir, nas práticas educativas, as significações produzidas pelas próprias crianças em seus contextos de vida e suas manifestações culturais e expressivas..

palavras-chave: educação infantil; infância; experiência.

\section{childhood, experience and education: notes from reflections on childhood}

\section{abstract}

This article brings reflections that involve childhood and experience from the area of education and, particularly, the considerations about research with young children and early childhood education. The notes impose limits on this place of study and delimits these as part of a criticism and self-criticism of education and the possibilities of consolidation of a Pedagogy of Childhood. In this direction, the article considers the analysis of the meaning of experience for the main educational theories or educational projects for childhood education, in order to lead to a demarcation of the contours of the educational experience in the institutionalized childhood. To do so, it presents some elements related to the educational experience as a social experience based on empirical studies that give visibility to the actions of children as part of their lives in children's collectives. Finally, it indicates as challenges for the possible consolidation of a Pedagogy of Childhood an approach of Pedagogy to children's manifestations, the child in situation and the possibilities of the educational processes if they are based on listening, dialogue and relationships, making it possible to include in practices educational, the meanings

\footnotetext{
${ }^{1}$ E-mail: eloisa.rocha@unoesc.edu.br

2 E-mail: marcia.simao@gmail.com
} 
produced by the children themselves in their life contexts and their cultural and expressive manifestations.

keywords: early childhood education; childhood; experience. infancia, experiencia y educación: apuntes a partir de reflexiones sobre la pequeña
infancia

resumen

El presente artículo trae reflexiones sobre la infancia y la experiencia a partir del área de la educación y, particularmente, realiza ponderaciones en torno a las investigaciones con niños pequeños de educación infantil. Los señalamientos imponen límites relativos a este lugar de estudio y los delimitan como parte de una crítica y autocrítica de la educación y de las posibilidades de consolidación de una Pedagogía de la Infancia. En esta dirección, en el artículo se analiza el sentido de la experiencia para las principales teorías o proyectos para la educación en la infancia, a fin de llevar a una demarcación de los contornos de la experiencia educativa en la infancia institucionalizada. Para ello, se presentan algunos elementos relativos a la experiencia educativa como experiencia social a partir de estudios empíricos que dan visibilidad a las acciones de los niños como parte de sus vidas en los colectivos infantiles. Por último, se indica como desafíos para la posible consolidación de una Pedagogía de la Infancia una aproximación de la Pedagogía a las manifestaciones infantiles, el niño en situación y las posibilidades de que los procesos educativos se guíen por la escucha, por la dialogicidad y por las relaciones, posibilitando incluir, en las prácticas educativas, las significaciones producidas por los propios niños en sus contextos de vida y sus manifestaciones culturales y expresivas.

palabras clave: educación infantil; infancia; experiencia. 
infância, experiência e educação: apontamentos a partir de reflexões sobre a pequena infância

O tema deste artigo surge de um debate em torno dos Estudos da Infância e da Pedagogia na busca de consolidação de espaços de diálogo que ampliem as perspectivas de análise sobre a infância e sua educação para além de um monorreferenciamento ${ }^{3}$ teórico disciplinar.

Tratar de infância e experiência a partir da área da educação e, particularmente das reflexões em torno das pesquisas com crianças pequenas e de educação infantil, nos impõe limites relativos a este lugar de estudo e delimita estes apontamentos como parte de uma crítica e autocrítica da educação e das possibilidades de consolidação do que temos definido como uma Pedagogia da Infância. Nesta direção, tomar para esta reflexão a análise do sentido da experiência para as principais teorias educacionais ou projetos educativos para a educação na infância, poderia nos levar apenas a uma demarcação dos contornos da experiência educativa na infância institucionalizada.

Para escapar desta perspectiva excessiva, no sentido dos limites e do impossível, retomamos, para inspirar, um pequeno texto de contracapa, produzido para o livro bordados sobre brincadeiras, denominado Netos e avós, memórias de brincadeiras:

Brincadeiras, bordados, avós e netos se encontram no caminho construído pela dimensão criativa, expressiva e lúdica que ultrapassa o enredamento da vida comum. Os encontros entre gerações para brincar criam um tempo de suspensão das amarras sociais voltadas para o utilitarismo e abrem espaço para a reiteração e o extraordinário envoltos no mistério do domínio do conhecido e no fascínio do improvável, numa trama de divertimento, comicidade e imaginação. Entre gerações, as brincadeiras preservadas na memória permitem realizar o desejo de estar juntos, explorando tessituras que confrontam o certo e o incerto, ordem e a desordem na busca do belo, mas também e muitas vezes a prazerosa repetição do mesmo. Benjamin nos ensina que as crianças (próximas aos mágicos e aos loucos), refazem a história de cada peça, pedra, toco, retalho e resto. Bordadeiras também. Brincadeiras oferecem aos avós, chances redobradas de rebordar a vida nos encontros com seus netos. (ROCHA, 2015).

\footnotetext{
3 Usamos este termo - monorreferenciamento em oposição ao que alguns pesquisadores da educação vêm definindo como multirreferencialidade - para maior aprofundamento ver Ardoino (1998) apud Dalpiaz (2015).
} 
Estes sentidos parecem estar distantes daqueles que contornam a experiência da infância nos contextos que tem como finalidade a sua educação. Pois como disse Benjamin (2012), se é na infância, que reside a capacidade de reconhecer o novo, de estranhar-se e introduzir esse novo estranho no espaço simbólico, é a essa tarefa de construção simbólica que se encarrega a infância.

\begin{abstract}
Analiso, então, a importância de uma antropologia filosófica (nos termos que dela falava Walter Benjamin), perspectiva que, efetuando uma ruptura conceitual e paradigmática, toma a infância na sua dimensão não-infantilizada, desnaturalizando-a e destacando a centralidade da linguagem no interior de uma concepção que encara as crianças como produzidas na e produtoras de cultura (KRAMER, 1996, p. 14).
\end{abstract}

Para Benjamin (2012), a morte da experiência significa a morte da história, de uma história residual, dos vencidos, dos fenômenos marginais da vida cotidiana. Seria a eterna tentativa de apagamento de tudo que é história, que é tradição, seria esse apagamento sutil e conformado em nome de tudo que é científico, de tudo que pode ser experimentado e não a experiência do sujeito. $\mathrm{Na}$ vida cotidiana a massificação das informações, das imagens, a produção em série da indústria cultural acaba por alcançar uma padronização das subjetividades e uma aniquilação da experiência.

Noutra direção, quando a experiência é entendida como aquilo que pode ser transmitido de geração em geração, relaciona o ato de transmitir a um ato educativo, cerne da formação humana.

Tomadas estas referências, o que dizer das formatações pedagógicas e dos projetos de educação cada vez mais estandardizados (dos materiais "educativos" aos padrões de interação)? Num processo crescente de institucionalização educativa, quais as possibilidades de experiência na infância contemporânea? De que forma podemos sustentar a perspectiva de consolidação de uma subárea, denominada como uma Pedagogia da Infância, com o uso de um termo que temos insistido e que parece estar carregado de ambiguidades, na medida em que se alicerça em opostos - numa direção a Pedagogia e noutra a Infância? ${ }^{4}$

\footnotetext{
${ }^{4}$ Incluímos também, em nossas motivações para estas críticas e autocríticas, as indagações recém feitas por Manuela Ferreira da Universidade do Porto/PT que, em visita ao nosso Grupo de Pesquisa em março de 2017, expressou um incômodo quanto a esse alicerce em opostos.
} 
Se a experiência na infância é sempre uma experiência educativa, ela envolve sempre normatividade? Falar de experiência na/da infância implica levar em conta o tensionamento entre o normativo que é próprio da educação e o contingencial de que tem lugar a infância. Para além de um jogo de sentidos a expressão experiência educativa parece ter um caráter mais aberto, menos conformador, do que a educação da experiência, pretendida pelos modelos pedagógicos tradicionais.

Na Pedagogia, a experiência associa-se à ideia da experimentação, da ação prática, como manipulação do real e como experimento. Sempre de forma a dar a direção da ação e moldar a experiência. Recuperar pedagogias ativas, sobre roupagem de participativas, não rompe com os modelos clássicos e concepções tradicionais vinculadas ao enquadramento social.

Os espaços de educação institucionalizados dirigidos à pequena infância são marcados por uma "ação intencional" que definem previamente as experiências das crianças. Este processo apresenta constrangimentos e normas próximos daqueles típicos das organizações totais, com fortes limites de tempos, espaços e materiais, mas que, simultaneamente, também apresenta um conjunto de possibilidades, sobretudo de ação social, próprias da vida em coletivo.

A inevitabilidade dos processos educativos que envolvem as novas gerações e a crença das velhas gerações de que aquelas sejam beneficiadas das construções subjetivas produzidas por um coletivo social - como a linguagem e os conhecimentos - tidos como já dadas (ditos, produzidos pela humanidade), conduz os projetos educativos sobretudo para os resultados e os pontos de chegada prévios - com vistas à assimilação do que já está dado. Desnecessário dizer o lugar que estes sentidos passam a ocupar com a atual dominante revalorização do sucesso e da meritocracia que pauta as metas educacionais.

Na pedagogia moderna, os objetivos voltados para a educação das crianças se orientam, sobretudo, para a assimilação de modelos e transmissão de uma determinada acumulação, reconhecida socialmente e valorizada culturalmente num contexto de manutenção hegemônica. As variações de sentido, modelos e 
métodos, ora voltados mais para os processos, ora voltados mais para os fins, ora orientados pela direção adulta, ora para uma maior atenção à ação da criança, não escapam destes propósitos conformadores.

Por vezes, temos visto que a ênfase na participação da criança, pretende apenas tornar melhor seu caminho para um ponto de chegada já definido e, cujo limite de terminalidade, vai sendo deslocado conforme o que os interesses de legitimação passam a exigir e que não são, tal como se anunciam, melhores e maiores. Ao contrário, vemos um movimento de limitação constante e crescente, com novas roupagens, mas continuamente no sentido contrário das possibilidades humanas e das potências da infância.

Se a infância representa uma possibilidade humana - na sua potência - a educação representa, em alguma medida, a configuração de uma formação pautada no constrangimento e, no limite, marcados pela fragmentação das dimensões humanas, acentuada ainda por parcializações disciplinares.

Como uma forma de produção de uma crítica interna a própria área da educação e da educação infantil - que não é nova - gostaríamos de pontuar alguns limites e possibilidades de uma experiência educativa na infância a partir da confrontação com a ideia de experiência social de Dubet (1994), como aquela que se dá na vida em coletivo, na educação das crianças pequenas.

Esta confrontação exige, de certo modo, uma aproximação com a ideia de encontrar na experiência o sentido compartilhado. Para Dubet (1994, p. 96): “Existe na experiência social alguma coisa de inacabado e de opaco, porque não há adequação absoluta da subjetividade do ator e da objetividade do sistema". Para ele, a experiência, como noção corrente, é ambígua, vaga e evoca contrários, ou seja, a experiência se apresenta como algo individual e, ao mesmo tempo, como a recobertura da consciência individual pela sociedade: “A experiência social não é nem uma esponja nem um fluxo de sentimentos e emoções, ela não é a expressão de um ser ou de um puro sujeito, pois que é socialmente construída" (DUBET 1994, p. 103). 
Se para Dubet (1994, p. 104) “a experiência [...] é na maior parte dos casos, puramente individual, é certo que ela só existe verdadeiramente, aos olhos do indivíduo, na medida em que é reconhecida por outros, eventualmente partilhada e confirmada por outros". Esta ideia permite pensar a experiência e a educação na / da infância como algo que não se reduz nem à funcionalidade de uma instituição (tais como creches e escolas), nem à dominação extrema; pura interiorização dos códigos culturais. Isto nos permitiria pensar numa brecha "como uma incitação para se passar das categorias "clássicas" da ação às da experiência social, acentuando a necessidade criada aos indivíduos de construírem uma ação própria" (DUBET, 1994 p. 100; grifos no original).

Há algum tempo também tem se colocado para nós da Educação, um impasse em relação ao nosso desconhecimento sobre a experiência das crianças nos contextos coletivos de educação, assim é que também temos buscado aproximações conceituais em torno da linguagem, do Outro, da dialogia - em Walter Benjamin e Mikhail Bakhtin. Esta busca de elementos para indicação de caminhos de uma educação da infância, na contracorrente das amarras estruturais, pretende consolidar, no interior de uma área ou subárea da educação, uma preocupação com a infância ausente nas teorias educacionais postas.

Os esforços em buscar responder a propósitos alheios tem nos feito retomar rotas ultrapassadas - que inclui teorizações da educação - com base em perspectivas polarizadas no indivíduo visto no seu isolamento social e também, com base em perspectivas de transmissão cultural já dada de forma verticalizada e definindo rigorosos pontos de chegada.

Esta questão está ligada a um desafio central: a realização de projetos educativos em contexto de extrema desigualdade e injustiça social e, a urgência da orientação educativa para aquelas/es que enfrentam cotidianamente a responsabilidade por milhões de crianças brasileiras de 0 a 10, que frequentam a educação infantil e as escolas.

Retomando a busca de compreensão sobre as possibilidades da experiência infantil em contextos educativos coletivos, temos também enfrentado o desafio do 
diálogo disciplinar para inaugurar caminhos para uma ação educacional inevitável e ao mesmo tempo potente, rememorando a indicação de Faria (1999), que já nos alertava, na década de 1980, para o tensionamento entre regulação e liberdade que constitui o processo educativo. Ainda que, em toda e qualquer prática educativa, haja algum controle da ação e alguma subordinação, ao conviver com o binômio atenção/controle, há também um conjunto de possibilidades de liberdade de expressão, de ação e de participação. Estas possibilidades não estão dadas no repertório de lógicas educativas e vêm exigindo a construção de estratégias permanentes de conhecimento das crianças, com base em diálogos disciplinares.

Nos últimos anos, temos buscado conhecer as dinâmicas das relações educativas, tendo como referência as próprias crianças como legítimas interlocutoras, contrariando sua posição como mero objeto da intervenção educativa. Identificado com aquela mesma direção dada por Brandão (1985) em suas lições antropológicas, nada usuais para aquele momento na década de 1980, entre pesquisadores da educação. Preocupado em fornecer conhecimentos e material crítico para experiências de relações entre arte e educação, sugere uma abordagem de pesquisa da criança em situação, ou seja, da pesquisa sobre a criança “em seu próprio universo cultural de significados, de vida e de criatividade [...] recolocar na cultura a criança. Reaprender a encontrar ali os sinais de sua presença ativa e participante". (BRANDÃO, 1985, p. 137).

Nas palavras de Brandão (1985, p. 137; grifos no original): “Um novo campo interdisciplinar, agora integrando os avanços ocorridos desde então até hoje poderia ser capaz de investigar os importantes 'espaços de silêncios' que, de modo isolado, nenhum tipo de teoria ou de pesquisa está sendo capaz de desvelar". Buscando esses 'espaços de silêncios' é que temos conduzido, nos últimos anos, diversas pesquisas em que, tendo como referência as próprias crianças, buscamos conhecer as dinâmicas das relações educativas como experiência social para as crianças. 


\section{experiências educativas a partir da perspectiva das crianças nas pesquisas}

Como forma de concluir destacaríamos ainda alguns elementos relativos à experiência educativa como experiência social e suas relações com alguns estudos empíricos que temos realizado e que dão visibilidade às ações das crianças como parte de suas vidas nos coletivos infantis, pautadas na convivência, na expressão, no lúdico e prazeroso, no mistério do domínio do conhecido e no fascínio do improvável, na criação do novo.

Lessa e Rivero (2016) 5 ao apresentarem um panorama abrangente de pesquisas desenvolvidas recentemente por integrantes do nosso Grupo de Pesquisa, recuperam pesquisas que têm procurado contemplar as perspectivas das crianças sobre diferentes temáticas que envolvem dimensões sociais e pedagógicas. As autoras apontam que ao considerar a perspectiva das crianças nas pesquisas educacionais abrem-se caminhos para instaurar a reflexão acerca de práticas pedagógicas mais democráticas que permitam experiências educativas mais próximas de um efetivo exercício da cidadania na infância. A exemplo da pesquisa desenvolvida por Agostinho (2010), em que a autora argumenta que para as experiências educativas "[...] a participação para os meninos e as meninas de pouca idade tem de ser pensada como prática de cidadania vivida, como vivências de cidadania, num ativo envolvimento e compartilhamento de poder para estruturação dos cotidianos de vida coletivo" (AGOSTINHO, 2010, p. v). A pesquisa também sinaliza que, para chegarmos aos conhecimentos necessários acerca das crianças e de suas experiências educativas como experiência social, é preciso: “[...] apreender todos os conteúdos expressos pelos diversos canais comunicacionais", entre eles, a “[...] dimensão corporal, do afeto, do humor, das culturas infantis e da produção cultural das crianças [...]", compreendidos como "[...] modos de participação delas em seus contextos de vida" (AGOSTINHO, 2010, p. v). Para a autora, à medida que exercitam sua autonomia as crianças

\footnotetext{
${ }^{5}$ Fazemos aqui, um agradecimento especial, às pesquisadoras Andréa Rivero e Juliana Lessa Schumacker pelo diálogo profícuo nas reflexões sobre o conceito de experiência e por disponibilizarem o texto apresentado do V Seminário de Grupos de Pesquisa sobre crianças e infâncias - Grupeci em que reúnem um conjunto de pesquisas realizadas por integrantes de nosso grupo de pesquisa: Núcleo de Estudos e Pesquisas da Educação na Pequena Infância NUPEIN/CED/UFSC.
} 
expressam seus pontos de vista e negociam a estruturação de seus mundos de vida, dão visibilidade a sua capacidade e interesse em participar, "indicando às práticas pedagógicas, esse importante princípio a ser considerado na sua execução" (AGOSTINHO, 2010, p. 297).

Já a pesquisa realizada por Lessa (2011) direcionou seu olhar para as experiências educativas vividas no espaço-tempo da alimentação na educação infantil. Para tanto, acompanhou um grupo de crianças com idade entre 3 e 4 anos nos seus momentos de alimentação durante a jornada da educação infantil de tempo integral. Ao analisar como são tecidas as relações sociais durante as práticas alimentares das crianças, Lessa (2011), caracteriza o refeitório como um dos espaços de socialização da infância, concebendo esse processo a partir de uma releitura crítica do conceito de socialização, sustentado nos estudos da Sociologia da Infância, que se opõe à visão de passividade da criança. A autora, ao evidenciar a ação social das crianças no espaço da alimentação na creche, sugere a necessidade de um maior aprofundamento sobre a perspectiva delas, de modo a construir indicativos para pensar as experiências educativas em torno desses momentos na educação infantil, sendo que são marcadas pelas experiências sociais e pessoais das crianças e dos adultos.

Se a pesquisa de Lessa (2011) analisou as experiências educativas e as relações tecidas no espaço do refeitório da educação infantil, a dissertação de Bezerra (2013) teve como objetivo "investigar os usos e os significados dados pelas crianças aos espaços da creche". Para a pesquisadora, a qualidade do espaço da creche é proporcional às possibilidades de experiências significativas que as crianças encontram nele. Para as análises das experiências educativas vividas pelas crianças no contexto investigado, os dados gerados foram confrontados com os critérios de qualidade para os espaços da educação infantil, apresentados nos documentos oficiais e na produção científica recente. A partir das observações junto a um grupo de crianças com idade entre 4 e 5 anos, Bezerra (2013) analisou os diversos espaços que compõem o contexto da educação infantil e ressalta que “[...] o lugar se constitui a partir da ocupação, do usar, significar e das relações 
estabelecidas entre crianças e adultos com o espaço e entre elas. As crianças, ao se apropriarem do espaço da creche, o transformam em um lugar de vida, de brincadeira, de cor, de movimento, de expressão, um lugar da criança" (BEZERRA, 2013, p. 204-205; grifos da autora).

$\mathrm{Na}$ pesquisa, entre os espaços qualificados pelas ações das crianças, sobressaíram as experiências educativas vividas na horta, no corredor e no banheiro da creche. Espaços estes que as crianças tornam lugares únicos, ao manifestarem outros significados: que ora se diferem, ora se ampliam, ora se confrontam com o sentido socialmente reconhecido. Nessa direção, os dados analisados na pesquisa permitem indicar que as crianças, nos seus modos de ocupação e ação nos espaços da creche, criam estratégias para constituir lugares diversos daqueles indicados nos documentos oficiais que definem critérios para analisar a qualidade do espaço. Nesse sentido, a pesquisa de Bezerra (2013) impõe a necessidade de considerar nas experiências educativas e na definição dos critérios de qualidade, os indicativos manifestados pelas crianças, nos seus modos de ser e de viver nos espaços da educação infantil.

$\mathrm{Na}$ pesquisa defendida por Mafra (2015), a autora buscou conhecer particularidades das experiências educativas vivida pelas crianças de um grupo com idade entre 3 e 5 anos, focando seu olhar para as formas regulatórias presentes no contexto educativo. A convivência no campo permitiu constatar que havia regras que eram estabelecidas às crianças de todos os grupos da instituição, a fim de organizar a rotina de maneira geral, enquanto outras eram restritas e específicas do grupo pesquisado. Para que a ordem fosse mantida e o caos contido, os profissionais da instituição lançavam mão de instrumentos e estratégias, exigindo das crianças o cumprimento de regras institucionais, como: fazer silêncio, não correr, comer de boca fechada, não levantar durante as refeições, respeitar o colega e as professoras, não empurrar, pedir o brinquedo emprestado, deitar para descansar na hora do sono, etc. Segundo Mafra (2015), este conjunto de estratégias pode ser traduzido como aparato de regras de convivência coletiva que são 
estipuladas de forma homogênea, para todas as crianças do contexto investigado e, assim vão compondo as experiências educativas das crianças.

Todavia, a pesquisa também indica que as crianças inserem elementos novos nessa dinâmica que compõem as experiências educativas e as experiências sociais e pessoais vividas na instituição, em particular, por meio da importância da participação das crianças que já frequentam a instituição há mais tempo ao contribuírem com o processo de inserção das crianças novas, que foram na pesquisa denominadas como novatas. Mafra (2015) aponta que o ingresso em uma instituição de educação infantil para as crianças novatas implica, um processo em que começam a ser inseridas, tanto pelos adultos quanto pelas demais crianças, na rede de regras que organizam o cotidiano educativo, enfim, uma primeira experiência social vivida em contexto coletivo. Os dados empíricos recolhidos por Mafra (2015) revelam que conhecer e dominar regras da instituição de educação infantil, algumas implícitas e evidentes, outras nem tanto, configuram-se como uma prática complexa para quem ingressa pela primeira vez numa instituição coletiva de educação.

Na pesquisa de doutorado, Buss-Simão (2012) dirige seu olhar para o corpo e as relações sociais das crianças pequenas em um contexto de educação infantil e busca compreender a complexidade do processo de socialização, a partir da perspectiva das crianças. Na pesquisa de campo, a experiência educativa vivida pelas crianças, revela a complexidade das relações como experiência social e a importância de uma concepção relacional de socialização para o reconhecimento e legitimação das ações e relações das crianças e dos conhecimentos que elas mobilizam ao interagirem cotidianamente, entre pares e também com os adultos.

Numa incursão nos espaços-tempos institucionais, a pesquisa revela indícios dos repertórios de competências sociais, relacionais, práticas corporais e discursivas que as crianças são capazes de mobilizar ao se confrontarem com uma lógica estrutural adulta, como também, com as diferentes lógicas de seus pares. Atenta às relações sociais, em particular, às relações sociais na instituição de educação infantil, Buss-Simão (2012), põe em evidência esse repertório de 
competências sociais na organização espaço-temporal, pensada e legitimada pelos adultos. A análise da pesquisa mostrou que nessa experiência educativa, por um lado, as crianças vão se apropriando de uma ordem institucional adulta ${ }^{6}$ reproduzindo-a junto aos seus pares, ao mesmo tempo em que também elas fazem uso seletivo desses conhecimentos criando e incluindo elementos, qualitativamente diferentes, dando emergência, a uma ordem instituinte das crianças, nas quais, na relação com os adultos, vão produzindo significados sociais e culturais.

A investigação de Buss-Simão (2012) mostrou que as crianças apontam possibilidades reais de gerarem atividades ou organizações novas e, qualitativamente diferentes, na busca por se afirmarem perante os enquadramentos primários definidos pela ordem institucional adulta. Essa possibilidade somente é admitida quando se concebe o processo educativo e sua aproximação a uma perspectiva de socialização em que as crianças são consideradas atores sociais plenos, que socializam-se também nas relações que estabelecem entre si. Ao mesmo tempo, sem desconsiderar que elas igualmente se socializam nas relações que estabelecem com as demais gerações que compõem a estrutura e as diferentes ordens sociais e culturais.

Ao acompanhar a experiência educativa das crianças, a partir da perspectiva delas, os episódios analisados na pesquisa indicam que é possível traçar uma aproximação com a Sociologia da Experiência proposta por Dubet (1994), ao considerar que as crianças percorrem um espaço de lógicas de ação em circulação, ou seja, tudo ao mesmo tempo, as quais vão compondo um conjunto de experiências sociais. Ao acompanhar as experiências sociais e pessoais das crianças no contexto educativo, a pesquisadora observa uma combinação de ações, em que, ao mesmo tempo, as crianças agem num sentido das lógicas de integração aderindo à ordem institucional adulta. Em outras situações, agem num sentido das lógicas estratégicas, apontando para interesses que entram em conflito com essa ordem institucional, a exemplo de quando, estrategicamente, aproveitam a ausência dos

\footnotetext{
6 Os conceitos ordem institucional adulta e ordem instituinte das crianças têm como base as contribuições de Ferreira (2002).
} 
adultos ou, espaços de ação dados por estes, para realizar coisas que gostam de fazer. E ainda, em outras situações, agem num sentido de subjetivação compondo uma lógica de ação que traz elementos qualitativamente diferentes à ordem institucional adulta (BUSS-SIMÃO, 2012).

$\mathrm{O}$ percurso realizado até aqui indica-nos, como bem pontuaram Lessa e Rivero (2016), que ao incluir a perspectiva das crianças nas análises das relações educativas nos contextos de educação e cuidado, algumas pesquisas trazem à tona a necessidade de maior atenção para os tipos de relações - entre as crianças, e entre elas e os adultos - que constituem as práticas pedagógicas e que, de um modo abrangente, demarcam o projeto educativo para a pequena infância e marcam a experiência educativa na pequena infância como uma experiência social.

As pesquisas realizadas em nosso grupo de pesquisa têm encarado o desafio teórico-metodológico de trazer à tona as perspectivas das crianças, a fim de compreender a experiência educativa vivida nos diversos contextos educativos, considerando que as crianças também fornecem indicativos a serem levados em conta nas reflexões. Como alertam Lessa e Rivero (2016) dentre os dados gerados pelas investigações, a participação das crianças no âmbito das experiências educativas reclama maior atenção, por tratar-se de uma participação, ainda, na maioria das vezes, concedida e tutelada.

Para finalizar e, considerando algumas questões já indicadas inicialmente neste artigo, cabe considerar que os principais desafios para a possível consolidação de uma Pedagogia da Infância se colocam justamente na aproximação da Pedagogia às manifestações infantis, a criança em situação e as possibilidades dos processos educativos se pautarem na escuta, na dialogicidade e nas relações, possibilitando incluir, nas práticas educativas, as significações produzidas pelas próprias crianças em seus contextos de vida e suas manifestações culturais e expressivas.

Conceber as experiências educativas como experiências sociais e a criança em situação e seus contextos de vida, traz o alerta de que as pesquisas realizadas no nosso grupo, mantém esse desafio de considerar o pertencimento social, pois há 
ainda, em nossas pesquisas, um certo apagamento das desigualdades sociais. Construir práticas pedagógicas mais dialógicas com as crianças envolve, não só, acolher e considerar as vozes e as suas manifestações expressivas que elas trazem de seus contextos de vida. Os conhecimentos e as culturas das crianças e, mesmo suas aprendizagens, vão se produzir por meio da ampliação desta relação de uma forma mais dialógica. Por isso, o desafio de uma Pedagogia da Infância pautada numa experiência educativa vista como experiência social e aproximada a uma pedagogia da escuta e das relações.

\section{referências}

AGOSTINHO, Kátia A. Formas de participação das crianças na Educação Infantil. Tese (Doutorado em Estudos da Criança - Especialidade em Sociologia da Infância) Instituto de Educação, Universidade do Minho, Braga/Portugal, 2010.

BAKHTIN Mikhail. Estética da criação verbal. São Paulo: Martins Fontes, 2003.

BAKHTIN Mikhail. Marxismo e filosofia da linguagem. São Paulo: Hucitec, 2006.

BENJAMIN, Walter. Magia e técnica, arte e política: ensaio sobre literatura e história da cultura (Obras Escolhidas v. I). São Paulo: Brasiliense, 2012.

BEZERRA, Mauricia Santos de Holanda. O Espaço na Educação Infantil: a constituição do lugar da criança como indicador de qualidade. 2013. Dissertação (Mestrado em Educação) - Centro de Ciências da Educação, Universidade Federal de Santa Catarina, Florianópolis. 2013.

BUSS-SIMÃO, Márcia. Relações sociais em um contexto de educação infantil: um olhar sobre a dimensão corporal na perspectiva de crianças pequenas. 2012. 312 f. Tese (Doutorado em Educação) - Universidade Federal de Santa Catarina, Florianópolis. 2012.

BRANDÃO, Carlos Rodrigues. A Educação como Cultura. Editora Brasiliense: São Paulo, 1985.

DALPIAZ, Luiza Helena. Educação permanente e políticas públicas: problematização de práticas e produção de conhecimentos. Roteiro, Joaçaba, Edição Especial, p. 173-192. 2015.

DUBET. François. Sociologia da experiência. Lisboa: Instituto Piaget, 1994.

FARIA, Ana Lúcia Goulart de. O Espaço Físico como um dos Elementos Fundamentais para uma Pedagogia da Educação Infantil. In: FARIA, Ana Lucia Goulart; PALHARES, Marina S. (Orgs). Educação Infantil Pós-LDB: rumos e desafios. Campinas/SP: Autores Associados, 1999. p. 67- 97.

FERREIRA, Maria Manuela Martinho. "- A gente aqui o que gosta mais é de brincar com os outros meninos!" - as crianças como atores sociais e a (re) organização social do grupo de pares no cotidiano de um Jardim de Infância. 2002. Dissertação (Doutoramento em Ciências da Educação), Faculdade de Psicologia e Ciências da Educação, Universidade do Porto. 2002. 
KRAMER, Sonia. Pesquisando a infância e educação: um encontro com Walter Benjamin. In: KRAMER, Sonia; LEITE, Maria Isabel. (Org.). Infância: fios e desafios da pesquisa. Campinas /SP: Papirus, 1996. p. 13-38.

LESSA, Juliana Schumacker, RIVERO, Andréa. Perspectivas das crianças nas pesquisas: caminhos para consolidação de uma pedagogia da infância. In: $5^{\circ}$ Seminário de Grupos de Pesquisa sobre crianças e infância - GRUPECI. Trabalho apresentado no $5^{\circ}$ Grupeci. Dez./2016.

LESSA, Juliana S. O espaço alimentar e seu papel na socialização da infância: o caso de uma creche pública. 2011. Dissertação (Mestrado em Educação) - Centro de Ciências da Educação, Universidade Federal de Santa Catarina, Florianópolis. 2011.

MAFRA, Aline Helena. "Aqui a gente tem regra pra tudo": formas regulatórias na educação das crianças pequenas. Dissertação (Mestrado em Educação) - Centro de Ciências da Educação, Universidade Federal de Santa Catarina, Florianópolis. 2015.

ROCHA, Eloisa Acires Candal. Contracapa. In: EVANGELISTA, Olinda; DURAN, Olga (org). Netos e avós, memórias de brincadeiras. UEM: Maringá, 2015.

recebido em: 28.09 .2017 aceito em: 01.12.2017 